\title{
Cyberbullying And Suicidal Behavior
}

\author{
Ina Dewi Ardiyani ${ }^{\mathrm{a}}$, Nalini Muhdi ${ }^{\mathrm{b}}$
}

${ }^{a}$ Official email address : inadewiardiyani@gmail.com

aMedical Doctor, Psychiatric Department, Faculty of Medicine, Airlangga University, Surabaya, 60132, Indonesia



\begin{abstract}
Bullying is a repeated exposure to negative actions from one or more individuals that are intended to harm others and involve an imbalance of power. Along with the development of technology, making online access easier and more widespread which resulted in the emergence of a form of online bullying known as cyberbullying. Cuberbullying can have a significant impact on individuals that is long-term and more severe than traditional bullying, both in terms of maladaptive emotional, psychological, behavioral, and physical. One of the most significant impacts is the emergence of suicidal behavior. Because the risk of cyberbullying is more dangerous, the risk of suicidal behavior will also be greater. This shows the importance of prevention and intervention in both cyberbullying and suicidal behavior. This effort requires the involvement of various parties including health, schools, parents, community, government, authorities or the law and anyone who knows about cyberbullying.
\end{abstract}

Keywords: Cyberbullying, Victimization, Suicidal Behavior

\section{Introduction}

Cyberbullying is an aggressive act of using information and communication technology to support intentional, repeated and hostile behavior by an individual or group that is intended to harm another person (Menesini et al., 2012). The prevalence of traditional bullying worldwide ranges from 16\%-36\%, while cyberbullying ranges from 10\%-57\% during childhood or adolescence. In 2010 the number of internet users in Indonesia increased from $30-35 \%$ to $40-45 \%$ in 2011. Internet access is getting easier with the increasing availability of smartphones and other supporting technologies. 50-80\% of internet users in Indonesia are young people aged 15-30 years who mostly use it for social networking (Safaria, 2016). The use of the internet and social media has both positive and negative benefits. Positive benefits are access to information, facilitate teaching and learning, increase levels of social support, and discuss issues. However, the presence of the internet and social media was also associated with negative benefits, including exposure to negative sexual material, cybercrime, cyberstalking and cyberbullying.

Most teenagers who experience cyberbullying also experience traditional bullying (Peng et al., 2019). Another study showed that the prevalence of adolescents experiencing traditional bullying was $71.4 \%$, traditional bullying and cyberbullying was $27.4 \%$, and cyberbullying alone was $1.1 \%$ (Thomas et al., 2017). A study of students in Indonesia stated that $80 \%$ of participants experienced cyberbullying and considered cyberbullying a stressful life event (Safaria, 2016). One study showed that most students aged 12-18 were cyberbullied at least twice in 1 year (Garett et al., 2016).

Suicide is a global phenomenon that causes individual death that occurs throughout life with a prevalence of $79 \%$ in both high and low income countries (WHO, 2020). Suicide is the second leading cause of death worldwide in individuals aged 15-29 years (WHO, 2020). In Indonesia, data compiled by the Sample Registration System (SRS) of the Research and Development Agency of the Ministry of Health in 2016 shows that the death rate due to suicide in Indonesia is $0.71 / 100.000$ population or 1800 people/year (Kementrian Kesehatan Republik Indonesia, 2019).

A study states that there is a relationship between cyberbullying and suicidal behavior. Cyberbullying 
is the second highest risk factor for suicidal behavior after the combination of traditional bullying and cyberbullying (Peng et al., 2019). Target victims of cyberbullying are 1.9 times more likely, while perpetrators are 1.5 times more likely to exhibit suicidal behavior than those who are not involved in cyberbullying (Hinduja and Patchin, 2018). This shows the importance of prevention and intervention for suicidal behavior and cyberbullying. Suicide prevention measures can also prevent cyberbullying (Hinduja and Patchin, 2018). This effort requires the involvement of various parties, including health services, schools, parents, the community, government, the authorities or the law as well as anyone who knows about cyberbullying. Several anti-cyberbullying intervention programs have shown a decrease in cyberbullying victimization by $14 \%$ and cyberbullying perpetrators by $10-15 \%$ (Gaffney et al., 2018). Early management of cyberbullying can prevent worse long-term effects, including suicidal behavior.

\section{Cyberbullying}

\subsection{Definition}

Bullying is an act of intimidation where the perpetrator deliberately seeks out the target victim with the aim of causing damage, repeatedly from time to time, aggressively, containing aspects of an imbalance of power between the perpetrator and the target victim, whether physical, social, psychological, or the number of people who involved (Campbell and Bauman, 2018). Cyberbullying was first widely recognized in 2000. The Cyberbullying Research Center defines cyberbullying as a form of bullying that occurs when someone repeatedly harasses, abuses, or makes fun of another person online or through a cell phone or other electronic device that causes harm, contains an element of imbalance. strength, and repeated victimization (Perdew, 2014). Cyberbullying is a form of "electronic bullying" or "internet bullying", following the same definition but with the use of the internet and/or electronic devices. The anonymity and skillful use of technology of actors can lead to an imbalance of power and freedom from social moral norms, while repetition arises because different people can view the action over a short period of time (Samara et al., 2017)(Mikhaylovsky et al., 2019). Cyberbullying can occur directly between the perpetrator and the target victim only, or indirectly when the perpetrator posts things about the target victim in some type of social format that is accessible to many people (Alhujailli and Karwowski, 2019).

\subsection{Comparison of cyberbullying with traditional bullying}

There are several features of cyberbullying that distinguish it from traditional bullying, including (Alim, 2016)(Foody et al., 2015)(Perdew, 2014)(Kota and Selkie, 2018)(Kenworthy, 2019)(Yulianti and Mada, 2019)(Campbell and Bauman, 2018) :

a. Cyberbullying happen anywhere, anytime (continuous access), and can be permanent

b. Information can spread quickly to a wide audience

c. Repetitive behavior, ease of copying material and distributing it widely

d. Perpetrators don't have to face their target victims because of their anonymity

e. It's harder to track down cyber bullies

f. Target victims of cyberbullying find it difficult to deal with bullies in real life

g. Target Victims of cyberbullying have difficulty interacting socially

h. Does not require that the perpetrator and the target victim are in the same geographic area

i. Cyberbullying contains verbal, emotional, psychological, and generally non-physical domains.

j. The tendency for attacks to be more destructive is due to the disinhibiting effect of online and the lack of oversight of online behavior. 


\subsection{Pathogenesis of cyberbullying}

According to the theory of Conservation of Resources (COR), a person experiences stress when he is threatened with losing something most valued, such as support and social interaction. Cyberbullying can cause stress because it threatens a basic human need, namely the need for belonging (belongingness). Repeated stressors over time that occur in cyberbullying can induce an emotional response and cause a decrease in performance and quality of life, either directly in the short term or in the long term and long lasting (Alhujailli and Karwowski, 2019). Biologically, when the subject is exposed to a stressor, the sympathetic nervous system and the hypothalamic-pituitary-adrenocortical (HPA) axis are activated, increasing the release of cortisol. The HPA axis is involved in the fight-or-flight response to threat or stress, which forms part of the biological balance that influences basic and primary reactions to threat mediated by autonomic responses. Targeted victims of cyberbullying who had higher levels of stress that lasted longer, resulting in a "sensitized threat" and altered function (activation) of the HPA axis. Cortisol secretion was found to be increased in cyberbullying compared to traditional bullying, due to the greater impact of cyberbullying stress. Target victims have higher stress scale scores than perpetrators and bystanders (Calvete et al., 2016). A number of neural structures are associated with bullying, including the amygdala, hippocampus, corpus callosum, anterior cingulate cortex, and prefrontal cortex. Bullying affects the fear system so that it activates the amygdala. Stress-induced increases in cortisol can also reduce neurogenesis in the hippocampus. Bullying also has an impact on the neurodevelopment of the prefrontal cortex, which plays a vital role in social brain development. Damage to this part of the brain results in changes in social conformity and well-being (Rossouw, 2014).

\subsection{Risk factors in cyberbullying}

Several factors that have tendency to experience cyberbullying including (Alim, 2016) :

1. Peer influence

Positive peer interaction and support are protective factors, whereas peer rejection and lack of social support are risk factors for cyberbullying.

2. Age and gender

The target of female victims is twice as high as that of men. Cyberbullying is greater in adolescents with an older age (16-19 years).

3. Education

Someone with low academic achievement is more likely to experience cyberbullying than those with high academic achievement.

4. Self esteem and self-image

Self esteemLow levels cause a lack of confidence in their own abilities and the instillation of bad thoughts by the target victim so that they are vulnerable to cyberbullying. Most of the victims were targeted by women because of their appearance, such as weight, while men because of their feminine or gay tendencies.

5. Internet usage

The higher the internet usage, the higher the risk of experiencing cyberbullying.

6. Publicity

The higher the publicity of a person, the more viewers, and the greater the risk of being exposed to cyberbullying. Public cyberbullying is more stressful than private cyberbullying (Alhujailli and Karwowski, 2019).

Protective factors such as personal competence; emotional management, self-concept, and high social 
competence; parental support and warmth; high socioeconomic status; school safety and satisfaction, and a safe environment. Risk factors include low self-esteem, self-control, social intelligence, and empathy; high levels of anxiety and aggression; lack of morals; single parent; negative family environment; sexual harassment and previous history of bullying (Ansary, 2020).

\subsection{Cyberbullying forms and media}

The media used for cyberbullying include text messages, email, chat rooms, websites, blogs, digital images, online games, social media (facebook, twitter, instagram, snapchat) or through features on mobile phones (Alim, 2016). Some forms of cyberbullying include flaming, harassment, denigration, impersonation/masquerading, outing and trickery, exclusion, cyberstalking, sexting, happy slapping, online polls, prank calls (Perdew, 2014) :

\subsection{Role in cyberbullying}

There are different roles in cyberbullying circles. There are different roles in cyberbullying circles (Kota and Selkie, 2018). The first is the target victim. Second, the perpetrator is directly involved with the target victim as an individual who sends text messages, posts, or harasses the target victim on social media or some other form of electronic contact. Third, the perpetrator's followers are engaged by distributing the offender's message or making further comments on the initial post. Fourth, passive supporters of the perpetrators who are involved by liking the posts of the perpetrators or in certain other ways that are on the side of the perpetrators. Fifth, a free audience who ignores bullying without doing anything (being "ignorant" with the situation). Sixth, passive defenders of the target victim where they may not like the perpetrator and think they should defend the target victim but are not directly involved with the situation, for example unfollowing the perpetrator on social media. Seventh, active defenders of the target victim, also known as a positive observer who directly engages with the perpetrator, as well as offering support by making comments directly under the perpetrator's posts or sending positive messages to the target victim (Kota and Selkie, 2018).

\subsection{Impact of cyberbullying}

Bullying can have an impact on physical, psychological, and academic. Psychologically, the target victim who is stressed and has prolonged fear due to continuous bullying will experience anxiety disorders, social anxiety, phobias, depression, PTSD, symptoms of headaches, lethargy, enuresis, tension, sleep disorders, psychosomatics, eating disorders, disturbed appetite, obsessive-compulsive disorder, Body Dysmorphic Disorder, negative view of the world and lack of self-confidence. This has an impact on interpersonal relationships and long-term quality of life. The more severe impact is the act of self-injury or suicidal behavior which is known as bullycide (Perdew, 2014). Bystanders and perpetrators also experience guilt (Samara et al., 2017). Victim perpetrators tend to have deep psychological problems and depression because of their role as perpetrators and targets of victims. Bystanders tend to feel anxious, depressed, helpless, or guilty for not being able to help or vice versa for helping the perpetrator. Cyberbullying is associated with psychological difficulties, external difficulties, and a poorer quality of life. Perpetrators do not understand the large psychological impact of their actions (Kenworthy, 2019). Physical impacts on target victims such as weight loss or gain, substance abuse, headaches, and stomachaches. There are academic difficulties such as school aggression, truancy, low academic achievement or academic decline in grades, and not feeling safe at school (Foody et al., 2015). Some of the signs in those who are targets of cyberbullying 
include:

1. Isolation and withdrawal from social interactions both at school and at home

2. Decreased academic grades, lack of interest in school activities

3. Nightmares, insomnia, bed-wetting, looking nervous, anxious, worried, sad and crying, lack of selfconfidence, irritability

4. More silent because they feel worthless and isolated

5. Behavioral changes, such as self-harm, drug and alcohol use, changes in appearance, being overly aggressive, and showing a sudden interest in violent media

6. Suddenly stops using his cell phone or computer, gets nervous about using his phone, or uses his computer or cell phone secretly or secretly.

The impact on cyberbullying is similar to traditional bullying, but higher stress levels, and lower selfesteem in cyberbullying. Cyberbullying is a predictor of suicide attempts in both target victims and perpetrators, and victimization is associated with increased suicidal ideation (Kota and Selkie, 2018). Target victims are 2-9 times more likely to consider suicide (Roth, 2015). Cyberbullying also affects the victim's concentration ability, lacks trust in others, fears for physical safety because the perpetrator is anonymous, continues to be wary of making sure the perpetrator is not mocking and fears that his cellphone or computer will alert to new bullying messages. The target victim is afraid of the computer, telephone or email, which is felt at any time and anywhere. Anxiety may still arise from worrying about continued harassment through public posts even when not online (Mioara et al., 2017). Cyberbullying is more closely related to suicidal behavior than traditional bullying (Campbell and Bauman, 2018).

\section{Suicidal Behavior}

Suicide is the act of someone who intentionally ends his own life. Suicidal behavior refers to the thoughts and behavior of a person who intentionally ends their own life (Connor and Nock, 2014). Suicide is a type of emergency in psychiatry. According to the American Psychiatric Association (APA) in the Diagnostic and Statistical Manual of Mental Disorders (DSM-5) it describes attempted suicide, suicidal ideation (suicidal thoughts), and non-suicidal self-injurious behavior. Based on DSM 5, the diagnosis of Suicidal Behavior Disorder is addressed to individuals who have made a suicide attempt in the last two years. Suicide comes from the Latin word for "self murder" which is defined as a fatal act that represents a person's desire to die. His judgments ranged between thoughts of suicide and his actions (Sadock et al., 2015).

\section{Cyberbullying and Suicidal Behavior}

There is a positive and significant relationship between cyberbullying in adolescents and suicidal behavior (Nikolaou, 2017)(Kim et al., 2019). Cyberbullicide is suicide directly or indirectly influenced by experiences with online aggression (Hinduja et al., 2010). Target victims of cyberbullying report 4 times higher suicidal ideation and 5 times higher suicide attempt. The target victim of cyberbullying feels that they have no safe place to escape, causing unbearable mental pain and lack of support, it can occur anywhere, anytime and is spread across a wide social network, making the target victim feel so isolated and helpless that increase the risk of suicide. Victims of cyberbullying were 7.85 times more likely to attempt suicide, and experienced greater and more frequent suicidal ideation (Nikolaou, 2017).

\subsection{Prevalence}

According to the Pew Research Center in Canada, $92 \%$ of people go online every day, and $71 \%$ use 
more than one type of social media, thereby increasing their exposure to cyberbullying. Studies on children aged 10-17 years, $14 \%$ of children reported experiencing cyberbullying more than once a month. In grades 7 $12,>40 \%$ experienced cyberbullying. Target victims of cyberbullying report greater depression, anxiety, risk behaviors, and suicide (Espelage and Hong, 2017). Adolescent girls are more likely to use social media to socialize than boys, so they are more likely to become victims of relational aggression, as well as being vulnerable to interpersonal stress and emotional problems, which exacerbates the impact of cyberbullying (Peng et al., 2019). There is a strong positive relationship between cyberbullying and suicidal ideation compared to traditional bullying (Geel et al., 2016). Target victims of both forms of bullying have the highest risk of suicide, target victims of cyberbullying as the second highest risk, and thirdly for traditional bullying (Peng et al., 2019). Target victims of cyberbullying, 17.7\% seriously considered attempting suicide, $14.6 \%$ made plans, $8.6 \%$ attempted suicide, and $2.8 \%$ attempted suicide in a manner that required treatment by a medical professional for 12 months, which is more common in girls than boys. Target victims of cyberbullying are 1.9 times and perpetrators 1.5 times more likely to commit suicide (Hinduja and Patchin, 2018)(Chang et al., 2019)(Kim et al., 2018).

\subsection{Suicide theory on cyberbullying}

Mental health is a protection against cyberbullying and suicidal behavior (Brailovskaia et al., 2018). Depression, substance use and cyberbullying behavior predict and mediate suicidal behavior (Sampasakanyinga et al., 2014)(Betts, 2016). Thomas Joiner's interpersonal theory states that there are two concurrent domains, namely the perceived burden (burdensomeness) and a low sense of belonging (belongingness) accompanied by a sense of desperation that these conditions do not change and interact with each other to lead to suicidal ideation (Klonsky et al., 2016).

The interpersonal theory of suicide states that suicidal ideation is caused by feelings of "thwarted belongingness" (TB) and "perceived burdensomeness" (PB). Bullying behavior is a manifestation of the obstruction of a positive sense of interconnectedness between the perpetrator and the target victim. Perpetrators are motivated by efforts to gain or maintain social status and become part of a peer group. Meanwhile, the target victim feels not accepted in the peer group as a marker of a disturbed sense of belonging (TB), thereby increasing the risk of suicidal behavior (Bauman et al., 2013). The presence of one of two interpersonal risk factors, namely TB as indicated by the perception of disconnection from others and a lack of reciprocal caring relationships, and $\mathrm{PB}$, which is indicated by self-hatred and the belief that death is more valuable to others than life will be increases the risk for passive suicidal ideation in the form of ideas about death. When a person simultaneously experiences TB, PB, and feels hopeless, the suicidal ideation will actively become a suicidal act. TB and PB also mediate the association between depressive symptoms and suicidal ideation. Cyberbullying shows that the target victim is rejected, unpopular, and unaccepted thereby increasing feelings of TB and PB, and can further increase suicidal ideation (Mitchell et al., 2018). Connectedness with the peer environment is experienced as a sense of belonging, involved, and supported by others in the peer environment. TB indicators show that the target of cyberbullying victims can inhibit a sense of connectedness with others (Kim et al., 2019).

The role of mass media in publicizing cyberbullying incidents can be a proximal factor in suicide. Vulnerable individuals then saw coverage of targeted suicide victims feeling that suicide was a viable solution. The media will continue to disseminate news of suicide where cyberbullying is seen as a contributor, even though cyberbullying alone is not necessarily the sole cause. When someone uses technology and it is used in social life, it is difficult to distinguish "online" and "offline" reality (Mikhaylovsky et al., 2019). "Suicide Contagion" refers to how one person's suicide can lead to another person's suicide attempt. This is often found in news coverage that reports about celebrity suicide widely, not only the amount of news but also 
the content of the news can affect the suicide rate. The American Foundation for Suicide Prevention has published guidelines on how journalists should not cover suicides. Public health professionals can proactively provide support resources for cyberbullying and suicide prevention to journalists. Journalists need to adhere to guidelines when covering suicide, avoid inflammatory or overly simplistic language, and tell stories of people who have overcome bullying (Young, 2018).

\subsection{Cyberbullying management}

Management of cyberbullying requires the role and involvement of many parties. Shared responsibility and a proactive attitude are required (Kowalski et al., 2008). Intervention programs are aimed at preventing cyberbullying before it occurs or reducing its impact after it occurs. The topics include how mindsets impact cyberbullying, recognizing irrational thinking and forming rational thinking, how cyberbullying occurs, how behavior can affect cyberbullying, how to overcome cyberbullying, skills to use safe technology, increase knowledge about media, develop self-efficacy, coping strategies, morals and empathy, as well as other positive skills; explain the role and consequences of cyberbullying, and their impact (Betts, 2016). The following steps should be considered by the target victim of cyberbullying (Feinberg and Robey, 2010) :

1. Calmly and firmly tell the offender to stop the behavior.

2. Ignore or block communication.

3. Make a copy of the material the abuser has posted and send it to the offender's parents for their help.

4. Clear the friends list in instant messages to reduce the number of people accessing the victim's email location.

5. File a complaint with the website, internet service provider or cell phone.

6. Ask the school authorities for help.

7. Contact a lawyer if the previous steps are not effective.

8. Call the police if cyberbullying poses a threat.

A healthy lifestyle (exercise, physical activity, diet, and adequate sleep duration) can overcome cyberbullying and suicidal ideation in adolescents so that it can be modified to reduce the risk (Rodelli et al., 2018). Education about online behavior and moral values is necessary before children start using technology. Legal intervention is necessary for serious and dangerous cases (Samara et al., 2017). Many social media companies tackle cyberbullying through reporting, blocking, software filtering, and automated detection systems (Ansary, 2020).

\subsubsection{The role of schools}

Schools play an important role in preventing cyberbullying (Foody et al., 2015). Things that schools can do include (Feinberg and Robey, 2010)(Betts, 2016)(Kenworthy, 2019) :

1. Identify cyberbullying in schools, where, what hinders reporting, create analysis and follow-up surveys for teachers and parents.

2. Assess threats to cyberbullying involving violence or suicide.

3. Include cyberbullying in a comprehensive school program.

4. Create a written policy on the use of students' internet and mobile communication devices.

5. Provide information to parents, students, and the public about preventing and responding to cyberbullying.

6. Teaching staff should also be trained in early warning signs to identify targets for cyberbullying victims. Active search of images, video clips, sound files, and other items used for cyberbullying. 
7. Establish a school task force responsible for cyberbullying interventions.

8. Develop working relationships on cyberbullying with local police and collaborate in educating students about cyberbullying and internet safety.

9. Fostering and facilitating to report cyberbullying to staff.

10. Document all examples, reports, and evidence of cyberbullying.

\subsubsection{The role of parents}

Most cyberbullying occurs at home when the child should be under parental supervision. Children rarely tell their parents about cyberbullying because they are afraid of being restricted or banned from using social networking sites, afraid of being ridiculed, or afraid that their parents will get involved (Kowalski et al., 2008). Supportive parent-child relationships (warmth, supervision, support, and parental involvement) can protect children from bad risks (Kim et al., 2019). The following is a summary of suggestions that can be given to parents (Betts, 2016)(Feinberg and Robey, 2010) :

1. Learn and pay attention to how children use technology;

2. Install content blockers or parental control filtering software and/or tracking programs if necessary;

3. Encouraging children to disclose cyberbullying;

4. Make a family agreement (when the child can be online, what to do, how much time, what to do if uncomfortable, how to stay safe, behave ethically and responsibly);

5. Understand privacy settings;

6. Negotiate and if necessary a contract on how much parents can know the child's online activity;

7. Discuss appropriate online behavior and its consequences and cyberbullying;

8. Keep the computer where it is easy to see;

9. Let children know that you can review their online communications;

10. Be aware of warning signs that children are being targeted by victims;

11. Encouraging internet security policy legislation.

\subsubsection{The role of health service providers}

Health care providers need to ask directly about involvement with bullying at school and online, in collaboration with various parties, including parents, teachers, schools, and the authorities (Espelage and Hong, 2017). Routine questions about the experience of bullying should be included in the consultation, recognizing verbal and nonverbal cues, and assessing trauma symptoms (Samara et al., 2017). Some things that can be done by health practitioners include (Espelage and Hong, 2017)(Kota and Selkie, 2018) :

1. Address cyberbullying in clinical settings by educating on cyberbullying prevention, screening and validating existing cyberbullying issues.

2. Include discussion of bullying as an anticipatory guide; cover the topic of proper and safe use of media; good social relations; prevention; identification; handling bullying and cyberbullying. This can be started as soon as the child begins to interact online.

3. Be aware of the Symptoms and Signs of Bullying (including cyberbullying) because patients rarely complain directly during consultations.

4. Prepare a patient clinical screening form before seeing a healthcare provider. Questions using a questionnaire are said to be more effective than asking directly. It is recommended to give each adolescent patient personal time with a doctor without parents because teenagers are more willing to open up. Frequently asked questions include: 1) How often have you been bullied or intimidated by others 2) How long, 3) Where, 4) How. 
5. Build rapport, trust, be considerate, and validate the patient's concerns, so that patients feel comfortable expressing their cyberbullying experiences.

6. Provide additional support resources and recommendations for patients and families.

7. Policy setting in cyberbullying often arises when there are critical and fatal cases, such as the target of a victim who died by suicide. The involvement of health care providers in promoting policies is important.

8. Provide and support education about cyberbullying. Collaborate with schools and families, as well as social media and blogs.

9. Collaborating with researchers, providing insights and experiences from clinical practice, providing access to patients in the clinic to be part of the study.

\subsubsection{The role of government}

The role of the government in this regard through the establishment of policies and the rule of law is needed for serious cases where a person's mental health is in danger such as cyberbullying which contains assault, indecent behavior, threatening, abusive, insulting, threats of violence, stalking, blackmail, harassment, obscene talk, pornography, which results in distress, anxiety, other psychological disorders, to the risk of suicide. Outreach by the government is important because not all perpetrators know that they have committed cyberbullying and do not understand the consequences. Through the legal aspect, when someone realizes that cyberbullying is a criminal offense may be a stronger prevention than just socializing. The function of government through legal provisions is to strengthen, not change one's social attitudes and behavior automatically, so education and socialization are still needed. Effective laws tend to strengthen cyberbullying prevention measures but do not at the same time change people's social attitudes. The government has an important role by incorporating cyberbullying into anti-cyberbullying policies through school program policies, establishing laws and regulations, and advocating anti-cyberbullying communities. The government's role in determining this policy is very important to strengthen, especially in the legal aspect, because often perpetrators still ignore the short-term and long-term negative consequences of cyberbullying if it is not accompanied by legal reinforcement (Samara et al., 2017).

Indonesia already has sufficient laws and regulations to crack down on this cyberbullying crime. However, existing laws and regulations have not been able to reach directly on cyberbullying because basically the Criminal Code was formed long before the development of cyber technology was initiated. So in order to accommodate the regulation regarding cyberspace and all matters related to it, including cyberbullying, Law Number 11 of 2008 concerning Information and Electronic Transactions was enacted. In this law, there are articles that are more appropriate to ensnare cyberbullying perpetrators ("Aspek Hukum Cyberbullying - Cyberbullying,” 2014).

A study outlines six recommendations for legislation addressing effective anti-cyberbullying policies, including (1) specific definitions of harassment, intimidation, and bullying by explicitly mentioning various technologies; (2) increasingly severe sanctions based on existing repetitions; (3) clear reporting policies; (4) clear investigative policies; (5) explicitly mentioning activities that occur outside of school which constitute cyberbullying; and (6) policies and procedures to prevent cyberbullying. This law holds educators and administrators accountable for effectively intervening, investigating, and reporting on, and implementing effective cyberbullying prevention programs (Ansary, 2020).

\section{Summary}

Cyberbullyingis a form of bullying that occurs when someone repeatedly harasses, abuses, or makes fun of another person online or when using a cell phone or other electronic device that causes damage, 
contains an element of power imbalance, and is repeated victimization. Cyberbullying is just as dangerous as traditional bullying, but traditional bullying has a physical component to its actions, while cyberbullying has an element of anonymity. Cyberbullying has a more damaging impact than other types of bullying. There is a positive and significant relationship between cyberbullying and suicidal behavior. Target victims of cyberbullying have the second highest risk of suicide after target victims of both types of bullying combined.

\section{Acknowledgments}

The authors wish to thank the Department of Psychiatry, Faculty of Medicine, Airlangga University, for supporting of this working group. No financial support was received for this study.

\section{References}

Alhujailli, A., Karwowski, W., 2019. Emotional and Stress Responses to Cyberbullying. Springer Int. Publ. AG 2, $33-43$. https://doi.org/10.1007/978-3-319-94622-1

Alim, S., 2016. Cyberbullying in the World of Teenagers and Social Media : Int. J. Cyber Behav. April 6. https://doi.org/10.4018/IJCBPL.2016040105

Ansary, N.S., 2020. Cyberbullying: Concepts, theories, and correlates informing evidence-based best practices for prevention. Aggress. Violent Behav. 50, 101343. https://doi.org/10.1016/j.avb.2019.101343

Aspek Hukum Cyberbullying, Cyberbullying, 2014.

Bauman, S., Toomey, R.B., Walker, J.L., 2013. Associations among bullying, cyberbullying, and suicide in high school students. J. Adolesc. 36, 341-350. https://doi.org/10.1016/j.adolescence.2012.12.001

Betts, L.R., 2016. Cyberbullying: Approaches, Consequences and Interventions. Palgrave Studies in Cyberpsychology, Notthingham, United Kingdom.

Brailovskaia, J., Teismann, T., Margraf, J., 2018. Cyberbullying, positive mental health and suicide ideation / behavior. Psychiatry Res. 267, 240-242. https://doi.org/10.1016/j.psychres.2018.05.074

Calvete, E., Peinado, J.M., Calvete, E., 2016. Relationship between cyberbullying roles, cortisol secretion and psychological stress. Comput. Human Behav. 70, 153-160. https://doi.org/10.1016/j.chb.2016.12.054

Campbell, M., Bauman, S., 2018. Cyberbullying: Definition, consequences, prevalence, Reducing Cyberbullying in Schools: International Evidence-Based Best Practices. Elsevier Inc. https://doi.org/10.1016/B978-0-12-811423-0.00001-8

Chang, Q., Xing, J., Ho, R.T.H., Yip, P.S.F., 2019. Cyberbullying and suicide ideation among Hong Kong adolescents : The mitigating effects of life satisfaction with family, classmates and academic results. Psychiatry Res. $274,269-273$. https://doi.org/10.1016/j.psychres.2019.02.054

Connor, R.C.O., Nock, M.K., 2014. Suicide 2 The psychology of suicidal behaviour. The Lancet Psychiatry 1, $73-85$. https://doi.org/10.1016/S2215-0366(14)70222-6

Espelage, D.L., Hong, J.S., 2017. Cyberbullying Prevention and Intervention Efforts : Current Knowledge and Future Directions. Can. J. Psychiatry Vol. 62, 374-380. https://doi.org/10.1177/0706743716684793

Feinberg, T., Robey, N., 2010. Cyberbullying : Intervention and Prevention Strategies. Natl. Assoc. Sch. Psychol. 1-4.

Foody, M., Samara, M., Carlbring, P., 2015. A review of cyberbullying and suggestions for online psychological therapy. Med. Sci. Sport. Exerc. 39, 42. https://doi.org/10.1249/01.mss.0000272354.41660.49

Gaffney, H., Ttofi, M.M., Farrington, D.P., 2018. Evaluating the effectiveness of school-bullying prevention programs: An updated metaanalytical review. Aggress. Violent Behav. (18), 1359-1789. https://doi.org/10.1016/j.avb.2018.07.001

Garett, R., Lord, L.R., Young, S.D., 2016. Associations between social media and cyberbullying : a review of the literature. MHealth 2, 46. https://doi.org/10.21037/mhealth.2016.12.01

Geel, M. Van, Vedder, P., Tanilon, J., Page, P., 2016. Relationship Between Peer Victimization, Cyberbullying, and Suicide in Children and Adolescents A Meta-analysis. Jama Pediatr. 168, 435-442. https://doi.org/10.1001/jamapediatrics.2013.4143 
Hinduja, S., Patchin, J.W., 2018. Connecting Adolescent Suicide to the Severity of Bullying and Cyberbullying. J. Sch. Violence 00, 114. https://doi.org/10.1080/15388220.2018.1492417

Hinduja, S., Patchin, J.W., Hinduja, S., Patchin, J.W., 2010. Bullying, Cyberbullying, and Suicide. Arch. Suicide Res. 1118, $206-$ 221,2010. https://doi.org/10.1080/13811118.2010.494133

Kementrian Kesehatan Republik Indonesia, 2019. Situasi dan Pencegahan Bunuh Diri. Pus. Data dan Inf.

Kenworthy, H., 2019. Cyberbullying in Education : A Literature Review. The University of Akron, Ohio, USA.

Kim, J., Walsh, E., Pike, K., Thompson, E.A., 2019. Cyberbullying and Victimization and Youth Suicide Risk : The Buffering Effects of School Connectedness. J. Sch. Nurs. 1-7. https://doi.org/10.1177/1059840518824395

Kim, S., Kimber, M., Boyle, M.H., Georgiades, K., 2018. Sex Differences in the Association Between Cyberbullying Victimization and Mental Health, Substance Use, and Suicidal Ideation in Adolescents. Can. J. Psychiatry 64, 1-10. https://doi.org/10.1177/0706743718777397

Klonsky, E.D., May, A.M., Saffer, B.Y., 2016. Suicide, Suicide Attempts, and Suicidal Ideation. Annu. Rev. Clin. Psychol. 12, $307-330$. https://doi.org/10.1146/annurev-clinpsy-021815-093204

Kota, R., Selkie, E., 2018. Cyberbullying and Mental Health. Technol. Adolesc. Ment. Heal. 89-99.

Kowalski, R.M., Limber, S.P., Agatston, P.W., 2008. Cyber Bullying. Blackwell Publishing, Victoria, Australia.

Menesini, E., Nocentini, A., Palladino, B.E., Berne, S., Ortega-ruiz, R., Ph, D., Calmaestra, J., Ph, D., Scheithauer, H., Ph, D., Schultzekrumbholz, A., Luik, P., Ph, D., Naruskov, K., Blaya, C., Ph, D., Berthaud, J., Smith, P.K., Ph, D., 2012. Cyberbullying Definition Among Adolescents: A Comparison Across Six European Countries. Cyberpsychology, Behav. Soc. Netw. Vol. 15, Number 9, 2012 15. https://doi.org/10.1089/cyber.2012.0040

Mikhaylovsky, M.N., Lopatkova, I. V., Komarova, N.M., Rueva, E.O., Tereschuk, K.S., Emelyanenkova, A. V., 2019. Cyberbulling as a new form of a threat: A physiological, psychological and medicinal aspects. Electron. J. Gen. Med. 16. https://doi.org/10.29333/ejgm/114268

Mioara, B., Dunarea, U., Galati, D.J., 2017. Psychological Effects of Cyberbullying in Adolescence Theoretical Analysis. https://doi.org/10.15303/rjeap.2017.si1.a61

Mitchell, S.M., Seegan, P.L., Roush, J.F., Brown, S.L., Sustaíta, M.A., Cukrowicz, K.C., 2018. Retrospective Cyberbullying and Suicide Ideation: The Mediating Roles of Depressive Symptoms, Perceived Burdensomeness, and Thwarted Belongingness. J. Interpers. Violence 33, 2602--2620 Agustus. https://doi.org/10.1177/0886260516628291

Nikolaou, D., 2017. Does cyberbullying impact youth suicidal behaviors? J. Health Econ. 56, 30-46. https://doi.org/10.1016/j.jhealeco.2017.09.009

Peng, Z., Klomek, A.B., Li, L., Su, X., Sillanmäki, L., Chudal, R., Sourander, A., 2019. Associations between Chinese adolescents subjected to traditional and cyber bullying and suicidal ideation, self-harm and suicide attempts. BMC Psychiatry 19, 1-8.

Perdew, L., 2014. Essential issues, Essential. ed. ABDO Publishing Company, Minnesota, USA.

Rodelli, M., Bourdeaudhuij, I. De, Dumon, E., Portzky, G., Desmet, A., 2018. Which healthy lifestyle factors are associated with a lower risk of suicidal ideation among adolescents faced with cyberbullying? Prev. Med. (Baltim). 113, 32-40. https://doi.org/10.1016/j.ypmed.2018.05.002

Rossouw, P., 2014. Bullying: a neurobiological perspective. Int. J. Neuropsychother. 1, 2-8.

Roth, R., 2015. Psychological Aspects of Cyberbullying. Univ. Graz Austria 113-119.

Sadock, B.J., Sadock, V.A., Ruiz, P., 2015. Synopsis of Psychiatry Behavioral Sciences/Clinical Psychiatry. Wolters Kluwer, New York, USA.

Safaria, T., 2016. Prevalence and Impact of Cyberbullying in a Sample of Indonesian Junior High School. TOJET Turkish Online J. Educ. Technol. 15, 82-91.

Samara, M., Burbidge, V., El Asam, A., Foody, M., Smith, P.K., Morsi, H., 2017. Bullying and cyberbullying: Their legal status and use in psychological assessment. Int. J. Environ. Res. Public Health 14. https://doi.org/10.3390/ijerph14121449

Sampasa-kanyinga, H., Roumeliotis, P., Xu, H., 2014. Associations between Cyberbullying and School Bullying Victimization and Suicidal Ideation, Plans and Attempts among Canadian Schoolchildren. PLoS One 9, e102145. https://doi.org/10.1371/journal.pone.0102145 
Thomas, H.J., Connor, J.P., Lawrence, D.M., Hafekost, J.M., Zubrick, S.R., Scott, J.G., 2017. Prevalence and correlates of bullying victimisation and perpetration in a nationally representative sample of Australian youth. Aust. New Zeal. J. Psychiatry 1-12. https://doi.org/10.1177/0004867417707819

WHO_ Suicide data PREVALENSI, 2020.

Young, R., 2018. How Journalists Cover Cyberbullying and Suicide_Public Health Post.

Yulianti, K.Y., Mada, U.G., 2019. Cyberbullying in Indonesian senior high schools : a study of gender differences. Inst. Educ. Univ. London 0-73. https://doi.org/10.13140/RG.2.2.26622.54081 